\title{
Evidence for independent molecular identity and functional interaction of the haemagglutinin and cysteine proteinase (gingivain) of Porphyromonas gingivalis
}

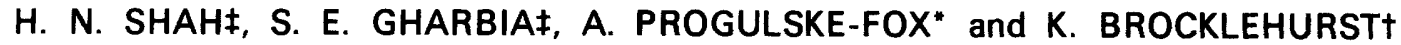

Department of Oral Microbiology. The London Hospital Medical College, University of London, Turner Street. Whitechapel, London E1 2AD, "Department of Oral Biology, University of Florida, Box J-424J.H.M.H.S.C., Gainesville, Florida 32666-0424, USA and +Department of Biochemistry, Queen Mary and Westfield College, University of London, Mile End Road, London E1 4NS

\begin{abstract}
Summary. The sequence of events involved in haemagglutination and lysis of erythrocytes by washed cells, vesicles and the culture supernate of Porphyromonas gingivalis strain W83 was monitored by ${ }^{51} \mathrm{Cr}$ release and transmission electronmicroscopy. All preparations, except capsular material and lipopolysaccharide, caused haemagglutination and, by a slow process of attachment and specific attack on the surface structures of the red blood cells, produced minute pores and eventual leakage of cellular contents. N-acetylglucosamine, $\mathrm{N}$ acetylgalactosamine and several other sugars such as glucose and sucrose had no effect on haemagglutination. Antiserum raised against a cloned haemagglutinin of $P$. gingivalis strain 381 inhibited the activity of strain W83 cells, vesicles and supernate. The antiserumneutralised supernate lost $70-80 \%$ of its hydrolytic activity towards $\alpha$-N-benzoyl-L-arginine4-nitroanilide but the residual activity behaved in a manner similar to the native supernate in that it was completely inhibited by the addition of 2,2 -dipyridyl disulphide and was fully restored upon addition of a low- $\mathrm{M}_{\mathrm{r}}$ mercaptan. Binding of the antiserum to the haemagglutinin epitope of $\boldsymbol{P}$. gingivalis still permitted titration of the active centre cysteinyl thiol group of the proteinase. Purified gingivain caused lysis of erythrocytes and was not neutralised by antiserum to the haemagglutinin. These results suggest that, although the haemagglutinin and gingivain are probably separate molecules, they are closely associated on the outer membrane of $\boldsymbol{P}$. gingivalis and may be functionally related.
\end{abstract}

\section{Introduction}

Porphyromonas gingivalis is unique among the genera Porphyromonas and Prevotella in possessing both a haemagglutinin and a potent membrane-bound proteinase. Both are regarded as potential virulence determinants for $P$. gingivalis; consequently their nature and function are currently under intensive investigations in several laboratories.

Many of the characteristics of the haemagglutinin of $P$. gingivalis have been reported ${ }^{1-6}$ but the nature of the molecule remains elusive. The haemagglutinin was first reported by Okuda and Takazoe ${ }^{7}$ and subsequently shown to comprise two major proteins of 40 and $60 \mathrm{Kda}^{6}$ Inoshita et $a l^{3}$ purified a haemagglutinin from the culture supernate of strain 381 and identified three major proteins $(24,37$ and $44 \mathrm{Kda}$ ). Two polypeptides of 43 and $49 \mathrm{Kda}$, associated with the haemagglutinating activity of strain

Received 11 April 1991; accepted 28 May 1991.

‡ Present address, which should be used for correspondence: Department of Oral Biology, Dalhousie University, Halifax, N.S., Canada B3H 3 J5.
ATCC 33277 , were also reported ${ }^{1}$ and antiserum to the haemagglutinin was demonstrated in the sera of healthy individuals and patients with chronic periodontitis. ${ }^{2}$ Recently, at least one haemagglutinin gene has been cloned in Escherichia coli ${ }^{8,9}$ and antisera to the clone reacted with a $43 \mathrm{Kda}$ protein of the cell lysates of $P$. gingivalis strains 381 and ATCC 33277. Polyclonal antiserum to the haemagglutinin of strain 381 (expressed in recombinant $E$. coli clone ST2) was previously shown to react mainly with the 43 - and 38$\mathrm{Kda}$ peptides and to a lesser extent with other peptides $(30,32,105$ and $115 \mathrm{Kda})$ in the cell lysate of its corresponding strain. ${ }^{9}$ Hybridisation studies have indicated that the cloned 381 haemagglutinin gene is present also in the other human isolates of $P$. gingivalis tested including strains W83 and W50 (Lepine and Progulske-Fox, unpublished observation). Furthermore, immuno-electronmicroscopy techniques revealed that the haemagglutinin resides on the cell surface of $P$. gingivalis. ${ }^{9}$ Its location was also confirmed indirectly by the use of a pleiotropic mutant of strain W50 (W50/BE1) which had lost its haemagglutinating activity, ${ }^{10}$ probably due to the absence of its outermembrane proteins. ${ }^{11}$ 
The nature of the proteinase of $P$. gingivalis is more controversial. The enzyme has been referred to simply as a protease, a serine protease, a thiol protease and most frequently as a trypsin-like enzyme. ${ }^{12-17}$ The use of the latter designation has led to a widespread use of trypsin inhibitors in experiments designed to determine the function of this enzyme. Recently, we have purified the extracellular proteinase of $\boldsymbol{P}$. gingivalis and presented evidence that the enzyme is not trypsinlike but is a cysteine proteinase for which we proposed the name "gingivain". ${ }^{18}$ We have shown previously that gingivain causes lysis of erythrocytes. ${ }^{6}$ It has been suggested that the haemagglutinin and the protease of $P$. gingivalis are the same molecule. ${ }^{4-6}$ In the present investigation, we extend our observations to elucidate the sequence of events that lead to the process of haemolysis. A series of experiments with monospecific antiserum to the cloned haemagglutinin of $P$. gingivalis and a thiol-specific inhibitor of gingivain, 2-2'dipyridyl disulphide, was designed to study the interaction of these two processes.

\section{Materials and methods}

\section{Growth conditions and vesicle preparation}

$P$. gingivalis strain W83 was grown in BM liquid medium containing haemin and menadione as described previously ${ }^{19}$ at $37^{\circ} \mathrm{C}$ in an atmosphere of $\mathrm{N}_{2}$ $70 \%, \mathrm{H}_{2} 20 \%, \mathrm{CO}_{2} 10 \%$. The culture supernate and cells after growth for 6 days were separated by centrifugation at $18000 \mathrm{~g}$ for $30 \mathrm{~min}$. Vesicle preparations were obtained from the culture supernate by $70 \%(w / v)$ followed by $40 \%(w / v)$ ammonium sulphate fractionation as described previously. ${ }^{6}$

\section{Capsular material}

Capsular material was extracted as described previously. ${ }^{20}$ Briefly, $500 \mathrm{mg}$ (wet weight) of cells were suspended in $100 \mathrm{ml}$ of $\mathrm{NaCl}(0.89 \%)$ solution, and mixed for $6 \mathrm{~h}$ at $4^{\circ} \mathrm{C}$. Two equivalent volumes of chilled acetone were added and the mixture was centrifuged at $20000 \mathrm{~g}$ for $1 \mathrm{~h}$ at $8^{\circ} \mathrm{C}$. The acetone layer was collected and concentrated under reduced pressure. The resulting precipitate was dialysed against double distilled water for 2 days and then dried under vacuum. Capsular material was further purified by column chromatography with Sepharose $4 B$ (Pharmacia, Uppsala, Sweden) and $50 \mathrm{mM}$, Tris-HC1, pH $8 \cdot 0$, as eluant. The eluate was monitored continuously for total carbohydrate content as described by Dubois et al ${ }^{21}$ A single major peak (c. $70 \%$ carbohydrate, $5 \%$ protein) was recovered and designated the capsular material. Protein concentrations were determined by the method of Lowry et al. ${ }^{22}$

\section{Cysteine proteinase (gingivain)}

The cysteine proteinase was prepared from the culture supernate, as described previously, ${ }^{6}$ by am- monium sulphate fractionation ( $70 \%$ saturated) and covalent chromatography ${ }^{23},{ }^{24}$ with activated thiopropyl-Sepharose 6B (Pharmacia). The enzyme was eluted by a concentration gradient of 10-20 mM cysteine in a buffer containing $300 \mathrm{mM} \mathrm{NaCl}$ and $300 \mathrm{mM}$ Tris$\mathrm{HCl}$, pH 8.0. Residual cysteine in the enzyme preparation was removed by gel filtration (Sephadex G25; Pharmacia) with $0 \cdot 1 \mathrm{M} \mathrm{KC1}$ as the eluant.

\section{Lipopolysaccharide (LPS)}

LPS was extracted from $1 \mathrm{~g}$ wet weight of $P$. gingivalis strain W83 cells by the method of Westphal and Jann. ${ }^{25}$ It was further purified by sequential treatment with DNAase, RNAase and pronase, followed by ultracentrifugation at $100000 \mathrm{~g}$ for $1 \mathrm{~h}$ as described previously. ${ }^{26}$ The crude LPS preparation was further extracted with phenol-chloroform-petroleum ether to remove traces of macromolecular contaminants as described by Galanos et $a .^{27}$ The purified LPS was electrodialysed ${ }^{28}$ to remove low- $M_{r}$ contaminants such as amines.

\section{Haemagglutination and haemolysis}

Haemagglutination was assayed in microtitration plates by mixing fresh sheep red blood cells $0.5 \%$ with serial two-fold dilutions of $50 \mu \mathrm{l}$ of test components in a total volume of $250 \mu \mathrm{l}$. $P$. gingivalis washed cells, vesicle preparation, culture supernate, LPS and capsular material were tested. Titres were reported as the endpoint dilution/ml of assay mixture. The experiments were repeated with ${ }^{51} \mathrm{Cr}$-labelled erythrocytes. Briefly, red blood cells were incubated in phosphatebuffered saline containing $12.5 \mu \mathrm{Ci}$ of chromium for $2 \mathrm{~h}$, after which, cells were repeatedly washed in buffer-saline until no radioactivity was measured in the washes. Inhibition of haemagglutination was measured under the above conditions except that the compounds tested were added serially, in two-fold dilutions, to the concentration of the highest dilution that caused haemagglutination. Carbohydrate solutions $(200 \mathrm{mM})$ tested for their inhibitory effects were D-glucose, D-galactose, D-fructose, D-mannose, Dsucrose, $\mathrm{D}-\mathrm{N}$-acetylglucosamine and $\mathrm{D}-\mathrm{N}$-acetylgalactosamine. Neutralisation with antiserum to the $P$. gingivalis haemagglutinin (ST2) was tested as above. The effect of the thiol-specific inhibitor 2,2'-dipyridyl disulphide (2PDS) was also tested at a pre-determined concentration that was just sufficient to cause complete inhibition in the assays with $\alpha-\mathrm{N}$-benzoyl-L-arginine4-nitroanilide (BAPNA; Sigma) as substrate. The effect of the removal of 2PDS by a low-M $\mathrm{M}_{\mathrm{r}}$ mercaptan on the haemagglutination inhibition was examined by incorporating $5 \mu \mathrm{l}$ of $20 \mathrm{mM}$ cysteine. Similarly, a mixture of $5 \mu \mathrm{l}$ of the cysteine solution and antiserum (titre of 1600) was also tested. Lysis of erythrocytes was assessed by the release of ${ }^{51} \mathrm{Cr}$ and electronmicroscopy. Samples for electronmicroscopy were negatively stained with phosphotungstic acid, $\mathrm{pH} 6 \cdot 5$, 
$2 \%$ and examined in a Phillips 400 transmission electronmicroscope as described previously. ${ }^{19}$

\section{Determination of catalytic activity}

Catalytic activity of the culture supernate and gingivain towards BAPNA was determined at $25^{\circ} \mathrm{C}$, in $100 \mathrm{mM}$ Tris- $\mathrm{HCl}$ buffer, $\mathrm{pH} 7 \cdot 4$, by initial rate analysis in a continuous spectrophotometric assay at $412 \mathrm{~nm}$ with a Gilford model 240 spectrophotometer, essentially as described by Malthouse and Brocklehurst. $^{29}$ The stock solution of BAPNA $(1.5 \mathrm{mM})$ was made up in water containing dimethyl sulphoxide $1 \% \mathrm{v} / \mathrm{v}$. A typical assay mixture contained $800 \mu \mathrm{l}$ of $0.1 \mathrm{mM}$ Tris- $\mathrm{HCl}$ buffer and $100 \mu \mathrm{l}$ of enzyme solution. The reaction was started by adding $100 \mu \mathrm{l}$ of BAPNA solution and the increase in $\mathrm{A}_{412}$ was recorded. Rates were calculated from the linear traces and converted into units of $\mathrm{M}^{-1} \mathrm{~s}^{-1}$ by $\varepsilon_{412}=8 \cdot 8 \times$ $10^{3} \mathrm{M}^{-1} \mathrm{~cm}^{-1}$ as described by Erlanger et al. ${ }^{30}$

\section{Reactions with 2,2'-dipyridyl disulphide (2PDS)}

2 PDS (Aldrich) was recrystallised twice from light petroleum (b.p. $60-80^{\circ} \mathrm{C}$ ) and had a m.p. of $58^{\circ} \mathrm{C}$. Inhibition experiments were performed by adding 2PDS solution ( $50 \mu \mathrm{l}$ of $1.48 \mathrm{mM})$ to assay mixtures in which catalytic activity had been demonstrated, and reactivation was achieved subsequently by adding $5 \mu \mathrm{l}$ of $20 \mathrm{~mm}$ cysteine solution. The cysteine residues in gingivain or the supernate were titrated by allowing $2 \mathrm{PDS}$ to react with each preparation at $\mathrm{pH} 4$ and $\mathrm{pH}$ 8 and determining the increase in $\mathrm{A}_{343}$.

\section{Results}

Washed cells, supernate and vesicle preparations of $P$. gingivalis grown in BM liquid medium for 6 days resulted in haemagglutination $(1060,40510$ and 87620 haemagglutination units/ml, respectively). Haemagglutination was not affected by hexoses (e.g., glucose, galactose and fructose), $\mathrm{N}$-acetylglucosamine or $\mathrm{N}$ acetylgalactosamine in accord with the recent findings of Kay et ${ }^{31}{ }^{31}$ for $P$. gingivalis strain W50. The above experiments were repeated with red blood cells labelled with ${ }^{51} \mathrm{Cr}$; release of ${ }^{51} \mathrm{Cr}$ was detected after exposure of the red blood cells to $P$. gingivalis components for $2 \mathrm{~h}$ and increased steadily up to $4 \mathrm{~h}$, after which no further changes were observed (fig. 1). ${ }^{51} \mathrm{Cr}$ release was accompanied by peculiar morphological distortions on the surface of the red blood cells as revealed by electronmicroscopy (fig. 2a). After incubation for $2 \mathrm{~h}$, the erythrocytes ruptured at some of these distorted sites (fig. 2b), followed by leakage of cell contents and, after $4 \mathrm{~h}$, only the membranes of the erythrocytes were visible. In wells containing gingivain and red blood cells only, direct lysis was clearly evident. It was possible to differentiate readily between lysis which

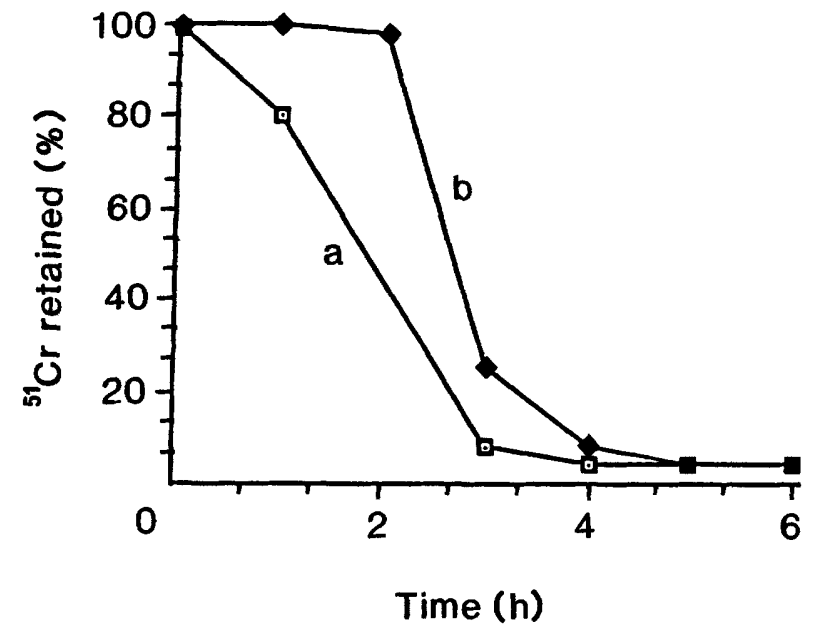

Fig. 1. ${ }^{51} \mathrm{Cr}$ release from sheep erythrocytes after incubation: (a) with gingivain; (b) following haemagglutination.

occurred in $<2 \mathrm{~h}$ and haemagglutination followed by lysis which became apparent after $4 \mathrm{~h}$.

Capsular material did not agglutinate erythrocytes, nor did LPS purified by enzymic treatment, ultracentrifugation and electrodialysis at concentrations up to $10 \mu \mathrm{g} / \mathrm{ml}$.

Antiserum against the cloned haemagglutinin of $P$. gingivalis strain $381^{9}$ inhibited the haemagglutinating activity of $\boldsymbol{P}$. gingivalis strain W83 cells, vesicles and supernate, whereas haemolysis due to gingivain remained unaffected. The hydrolytic activity of the supernate on BAPNA was completely inhibited by 2PDS, but was reactivated by addition of a low- $\mathbf{M}_{\mathrm{r}}$ mercaptan such as cysteine ( $20 \mathrm{mM}$ ) (fig. 3). However, the antibody-neutralised supernate (titre 1600) retained only $20-30 \%$ of its initial activity towards BAPNA (fig. 3). Similarly, this residual activity was completely inhibited by 2PDS and reactivated by the addition of cysteine (fig. 3). Spectrophotometric titration specifically of the active site cysteinyl thiolgroup is achieved by reaction with $2 \mathrm{PDS}$ at $\mathrm{pH} \mathrm{4.0}$ (see Brocklehurst ${ }^{32}$ for a description of the basis of this technique). At $\mathrm{pH} \mathrm{8.0,} \mathrm{the} \mathrm{absorbance} \mathrm{change} \mathrm{at}$ $343 \mathrm{~nm}$ was approximately two-fold greater than at pH 4.0 (fig. 4) which resulted from the additional reaction of a non-functional cysteinyl thiol group. These results are in accord with those obtained previously for purified gingivain. ${ }^{6}$

The addition of 2PDS inhibited the cysteine proteinase gingivain in the supernate, preventing both haemagglutination and cell lysis. This inhibitory effect was reversed by the addition of $20 \mathrm{mM}$ cysteine and after incubation for $4 \mathrm{~h}$, cell lysis was apparent. When a mixture of cysteine and antiserum was added, neither haemagglutination or cell lysis were apparent.

\section{Discussion}

The haemagglutinating activity of $P$. gingivalis has been reported by several workers. ${ }^{1-6}$ Recently, we 
a
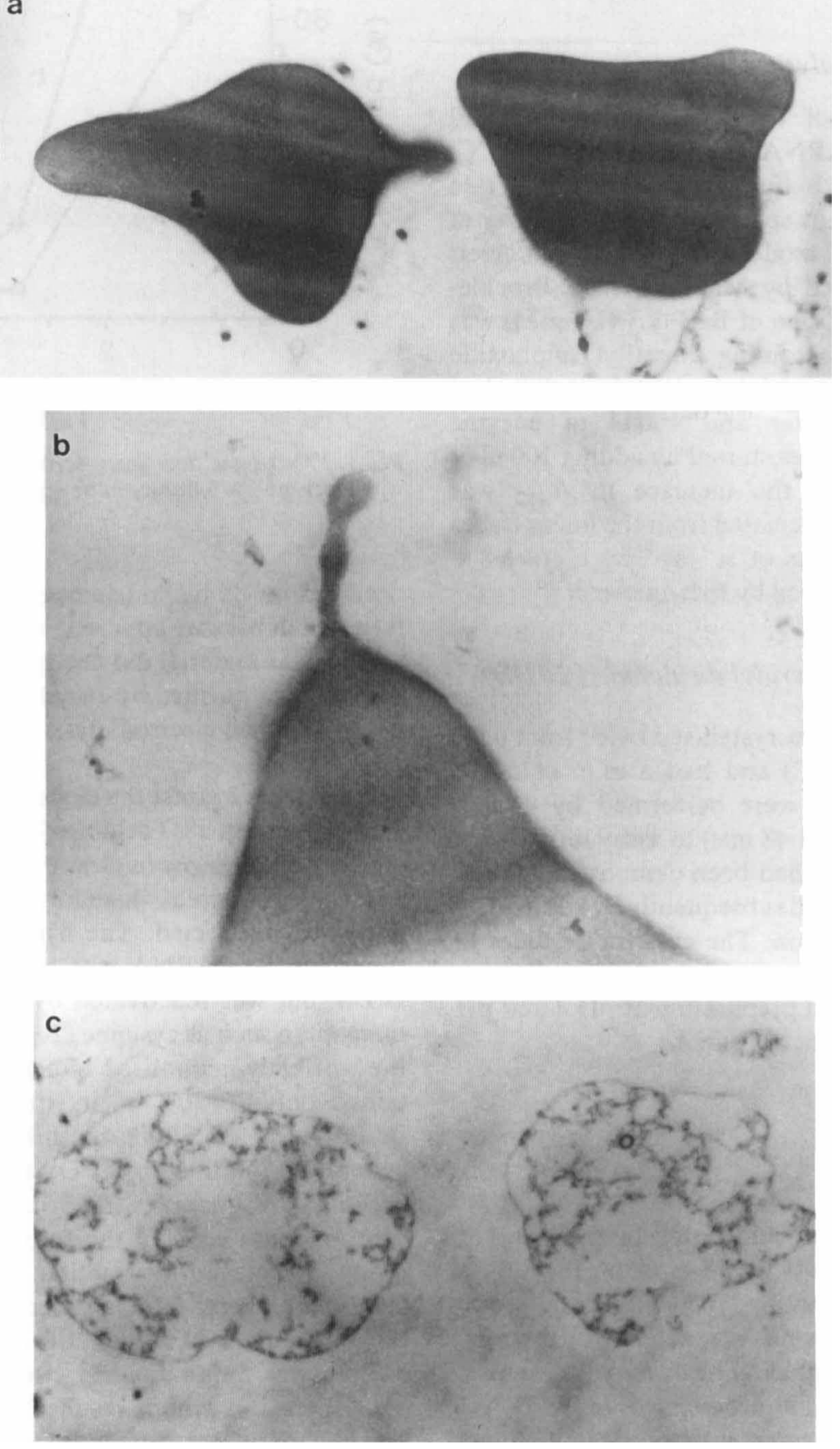

Fig. 2. Stages in the lysis of erythrocytes after treatment with $\boldsymbol{P}$. gingivalis cells, vesicles or supernate. (a) Red blood cells are grossly distorted with pronounced protrusions, but still intact, within $1 \mathrm{~h}(\times 8400)$. (b) Leakage of erythrocyte contents through minute pores, after $2 \mathrm{~h}(\times$ 22400 ). (c) Ghosting of red blood cells as a consequence of steps (a) and (b) resulting eventually in disintegration of the membranes after $4 \mathrm{~h}$ $(\times 8400)$.

have shown that haemagglutination is accompanied by lysis. ${ }^{6}$ In this study, the sequence of events leading to haemagglutination and lysis was followed over a period of $5 \mathrm{~h}$. Haemagglutination was not accompanied by simultaneous lysis, but rather a slow process of attachment and specific attack on the red-bloodcell surface components, leading to the production of minute pores and leakage of cellular contents of the erythrocytes.
P. gingivalis possesses surface components such as a capsule, fimbriae, LPS and outer-membrane proteins, some of which have been implicated in haemagglutination. ${ }^{1,2,5,31}$ In the present study, highly purified capsular material and LPS showed no haemagglutinating activity. Similarly, fimbriae of $P$. gingivalis have previously been shown to lack haemagglutinating properties. Growing evidence implicates a proteinlipid complex in the outer membrane in the mediation 


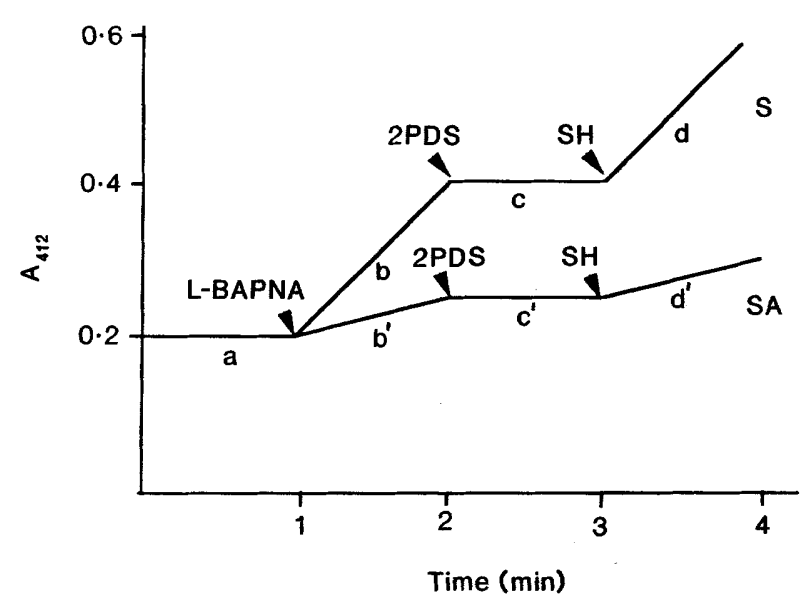

Fig. 3. Inhibition and reactivation of $\boldsymbol{P}$. gingivalis supernate (S) and supernate plus antiserum (SA). (a) The supernate or the supernate plus antiserum was continuously monitored at $412 \mathrm{~nm}$ until the baseline was unchanged. (b, $\mathbf{b}^{\prime}$ ) The addition of BAPNA to the assay mixture leads to an increase in absorbance at $412 \mathrm{~nm}$ due to the chromophore p-nitroaniline. (c, $\mathbf{c}^{\prime}$ ) Inhibition of hydrolytic activity towards BAPNA by the addition of stochiometric amounts of 2 PDS to the reaction mixture. (d, $d^{\prime}$ ) The addition of a low-M mercaptan (SH) such as cysteine resulted in reactivation of hydrolytic activity towards BAPNA.

of haemagglutination. ${ }^{5,7}$ Recent findings by Nishikata et al. ${ }^{4}$ showed, from proteinase-inhibitor studies, that the haemagglutinin of $\boldsymbol{P}$. gingivalis possesses proteolytic properties. This was supported by our previous finding that haemagglutination was inhibited by the thiol-blocking agent 2 PDS. ${ }^{6}$ These results suggest that haemagglutination and proteolytic activity are due to a surface molecule on $\boldsymbol{P}$. gingivalis cells, or vesicles secreted into the culture medium. Such a hypothesis requires that the haemagglutinin and the cysteine proteinase are situated in the outer membrane and extend beyond its surface to enable effective binding and proteolysis to occur.

The current study suggests that a haemagglutinin and proteinase may exist as separate but juxtaposed structural entities on the outer membrane, but may be functionally interdependent. Thus, when an excess of antiserum is added to the reaction mixture, $20-30 \%$ of the hydrolytic activity towards BAPNA remains (fig. 3); furthermore, the catalytic thiol group of the proteinase is still accessable to the 2PDS inhibitor (fig. 4). These results, together with the observations that purified gingivain does not cause haemagglutination, suggest that the antibody binds a neighbouring region of the outer membrane close to the enzyme surface. Binding of antibody close to the enzyme could reduce its catalytic activity by distortion of its conformation or by direct interference with substrate binding. The abolition of haemagglutination by the reaction of membrane-bound gingivain with 2PDS suggests that a part of the enzyme surface close to the catalytic site and the binding area of the enzyme might be involved in binding of antibody and haemagglutination. Derivatisation of the thiol group as a bulky 2-pyridyl

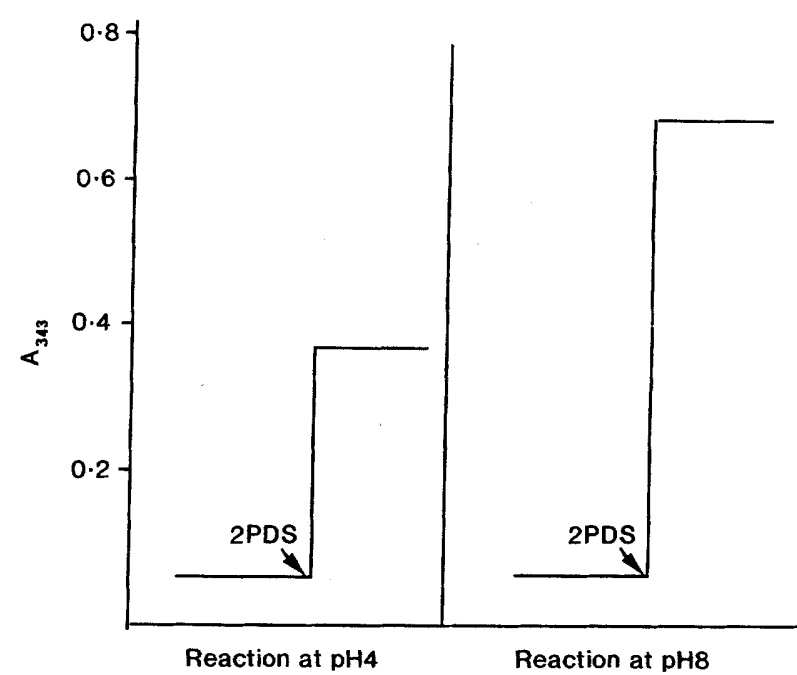

Fig. 4. Reaction of the thiol groups of gingivain with 2PDS to produce the chromophoric product, pyridine-2-thione $\left(\varepsilon_{343}=8080\right.$ $\mathrm{M}^{-1} \mathrm{~s}^{-1}$ ); (a) at $\mathrm{pH} 4 \cdot 0$, only the catalytically essential thiol group reacts rapidly; (b) at $\mathrm{pH} 8 \cdot 0$, both the catalytically non-functional thiol group and the catalytically essential thiol group react rapidly.

disulphide might result in steric shielding of the postulated adjacent part of the enzyme surface.

$P$. gingivalis has an obligatory requirement for haem, and its capacity to grow on blood-agar plates and hydrolyse haemoglobin indicate that these microorganisms can obtain haem directly from whole blood. Furthermore, $P$. gingivalis demetallates protohaem to produce protoporphyrin, which can be stored and utilised by the organism. This may be an important mechanism for the acquisition of iron, which is essential for the growth of most bacteria. ${ }^{33} P$. gingivalis has a requirement for iron in the ferrous form, ${ }^{34}$ but the oxidation state of iron in the porphyrin molecule of this species is not yet known. Physiological concentrations of free iron are well below that required by micro-organisms; hence the capacity to demetallate protohaem under conditions of haem excess may serve to redress this imbalance.

Haem has been shown both to increase the mean generation time and modulate the virulence of $P$. gingivalis, and pleiotropic haem-deficient mutants have reduced virulence in animals. ${ }^{35}$ The present results suggest that haemagglutination, followed by lysis of erythrocytes, may serve as a means of obtaining both haem and iron in vivo. Other members of the genus Porphyromonas lack the ability to either haemagglutinate or lyse erythrocytes, and this deficiency might partly explain their lower pathogenic potential. Free haemoglobin has been shown to increase the virulence of many opportunistic pathogens. ${ }^{33}$ However, haemoglobin is rapidly bound to haptoglobin in vivo and, therefore, is not freely available in serum (and presumably in crevicular fluid). $\boldsymbol{P}$. gingivalis has been shown to degrade several iron binding proteins, including haptoglobin. ${ }^{36}$ Thus further studies are required to determine whether this species can degrade haemoglobin-haptoglobin complexes. 


\section{References}

1. Boyd J, McBride BC. Fractionation of hemagglutinating and bacterial binding adhesins of Bacteroides gingivalis. Infect Immun 1984; 45 : 403-409.

2. Deslauriers $\mathbf{M}$, Mouton $\mathbf{C}$. Immunoreactivity in humans of Bacteroides gingivalis hemagglutinating adhesin $\mathrm{HA}-\mathbf{A g} 2$. Oral Microbiol Immunol 1990; 5: 302-304.

3. Inoshita E, Amano A, Hanioka T, Tamagawa $H$, Shizukuishi $S$, Tsunemitsu A. Isolation and some properties of exohemagglutinin from the culture medium of Bacteroides gingivalis 381. Infect Immun 1986; 52: 421-427.

4. Nishikata M, Yoshimura F, Nodasaka Y. Possibility of Bacteroides gingivalis hemagglutinin possessing protease activity revealed by inhibition studies. Microbiol Immunol 1989; 33: 75-80

5. Okuda K, Yamamoto A, Naito Y, Takazoe I, Slots J, Genco RJ. Purification and properties of hemagglutinin from culture supernatant of Bacteroides gingivalis. Infect Immun $1986 ; 54: 659-665$.

6. Shah HN, Gharbia SE. Lysis of erythrocytes by the secreted cysteine proteinase of Porphyromonas gingivalis W83. FEMS Microbiol Lett 1989; 61 : 213-218.

7. Okuda K, Takazoe I. Haemagglutinating activity of Bacteroides melaninogenicus. Arch Oral Biol 1974; $19: 415-416$.

8. McBride BC, Joe A, Singh U. Cloning of Bacteroides gingivalis surface antigens involved in adherence. Arch Oral Biol $1990 ; 35: 59 \mathrm{~S}-68 \mathrm{~S}$.

9. Progulske-Fox A, Tumwasorn S, Holt SC. The expression and function of a Bacteroides gingivalis hemagglutinin gene in Escherichia coli. Oral Microbiol Immunol 1989; 4: 121-131.

10. Shah HN, Seddon SV, Gharbia SE. Studies on the virulence properties and metabolism of pleiotropic mutants of Porphyromonas gingivalis (Bacteroides gingivalis) W50. Oral Microbiol Immunol 1989; 4: 19-23.

11. Haapasalo M, Shah HN, Gharbia SE, Seddon SV, Lounatmaa K. Surface properties and ultrastructure of Porphyromonas gingivalis W50 and pleiotropic mutants. Scand J Dent Res $1989 ; 97: 355-360$.

12. Loesche WJ, Syed SA, Stoll J. Trypsin-like activity in subgingival plaque. A diagnostic marker for spirochaetes and periodontal disease? J Periodontol 1987; 58: 266-273.

13. Minhas T, Greenman J. Production of cell-bound and vesicleassociated trypsin-like protease, alkaline phosphatase and $\mathrm{N}$-acetyl- $\beta$-glucosaminidase by Bacteroides gingivalis strain W50. J Gen Microbiol 1989 ; 135 : 557-564.

14. Smalley JW, Birss AJ. Trypsin-like enzyme activity of the extracellular membrane vesicles of Bacteroides gingivalis W50. J Gen Microbiol 1987; 133: 2883-2894.

15. Smalley JW, Birss AJ, Kay HM, McKee AS, Marsh PD. The distribution of trypsin-like enzyme activity in cultures of a virulent and an avirulent strain of $B$ gingivalis W50. Oral Microbiol Immunol 1989; 4: 178-181.

16. Sorsa T, Uitto VJ, Suomalainen K, Turto H, Lindy S. A trypsinlike protease from Bacteroides gingivalis: partial purification and characterisation. $J$ Periodont Res 1987; 22: 375380.

17. Yoshimura F, Nishikata M, Suzuki T, Hoover CI, Newbrun E. Characterisation of a trypsin-like protease from the bacterium Bacteroides gingivalis isolated from human dental plaque. Arch Oral Biol 1984; 29 : 559-564.

18. Shah HN, Gharbia SE, Kowlessur D, Wilkie E, Brocklehurst K. Gingivain a cysteine proteinase isolated from Porphyromonas gingivalis. Microbiol Ecol Hlth Dis 1991; 4: 319328.
19. Shah HN, Williams RAD, Bowden GH, Hardie JM. Comparison of the biochemical properties of Bacteroides melaninogenicus from human dental plaque and other sites. $J$ Appl Bacteriol 1976; 41 : 473-492.

20. Wilson M, Meghji S, Harvey W. Effect of capsular material from Haemophilus actinomycetemcomitans on bone collagen synthesis in vitro. Microbois $1988 ; 54: 181-185$.

21. Dubois M, Gilles KA, Hamilton JK, Rebers PA, Smith F. Colorimetric method for determination of sugars and related substances. Anal Chem 1956; 28 : 350-356.

22. Lowry $\mathrm{OH}$, Rosebrough NJ, Farr AL, Randall RJ. Protein measurement with the Folin phenol reagent. $J$ Biol Chem $1951 ; 193$ : 265-275.

23. Brocklehurst K, Carlsson J, Kierstan MPJ, Crook EM Covalent chromatography by thiol-disulfide interchange. Methods Enzymol 1974; 34: 531-544.

24. Brocklehurst K, Carlsson J, Kierstan MPJ. Covalent chromatography in biochemistry and biotechnology. Topics Enzyme Ferment Biotechnol 1985; 10: 146-188.

25. Westphal O, Jann K. Bacterial lipopolysaccharides extraction with phenol-water and further applications of the procedure. In: Whistler RL (ed) Methods in carbohydrate chemistry, vol 5. New York, Academic Press Inc. 1965: 83-91.

26. Iino $\mathrm{Y}$, Hopps RM. The bone-resorbing activities in tissue culture of lipopolysaccharides from the bacteria Actinobacillus actinomycetemcomitans, Bacteriodes gingivalis and Capnocytophaga ochracea isolated from human mouths. Arch Oral Biol 1984; 29 : 59-63.

27. Galanos C, Lüderitz $O$, Westphal $O$. A new method for the extraction of R lipopolysaccharides. Eur J Biochem 1969 9: $245-249$.

28. Galanos C, Lüderitz O, Reitschel ET, Westphal O. Newer aspects of the chemistry and biology of bacterial lipopolysaccharides, with a special reference to their lipid A component. In: Goodwin TW (ed) The biochemistry of lipids II (International review of biochemistry, vol 14). Baltimore, University Park Press. 1977: 239-335.

29. Malthouse JPG, Brocklehurst K. Preparation of fully active ficin from Ficins glabrata by covalent chromatography and characterization of its active centre by using $2,2^{\prime}$-dipyridyl disulphide as a reactivity probe. Biochem $J 1976 ; 159$ : 221 234.

30. Erlanger BF, Kokowsky N, Cohen W. The preparation and properties of two new chromogenic substrates of trypsin. Arch Biochem Biophys 1961 ; 95: 271-278.

31. Kay HM, Birss AJ, Smalley JW. Haemagglutinating and haemolytic activity of the extracellular vesicles of Bacteroides gingivalis W50. Oral Microbiol Immunol 1990; 5: 269274.

32. Brocklehurst $\mathbf{K}$. Two-protonic state electrophiles as probes of enzyme mechanism. Methods Enzymol 1982; 87:427-469.

33. Griffiths E. The iron-uptake systems of pathogenic bacteria. In: Bullen JJ, Griffiths E (eds) Iron and infection. Chichester, John Wiley and Sons. 1987: 69-137.

34. Barua PK, Dyer DW, Neiders ME. Effect of hemin limitation on Bacteroides gingivalis. Oral Microbiol Immunol 1990; 5: 263-268.

35. McKee AS, McDermid AS, Baskerville A, Dowsett AB, Ellwood DC, Marsh PD. Effect of hemin on the physiology and virulence of Bacteroides gingivalis W50. Infect Immun $1986 ; 52: 349-355$.

36. Carlsson J, Höfling JF, Sundqvist GK. Degradation of albumin, haemopexin, haptaglobin and transferrin, by black-pigmented Bacteroides species. J Med Microbiol 1984; 18: 3946. 